\title{
PENGENDALIAN MODUL STORAGE STATION BERBASIS SEQUENTIAL FUNCTION CHART
}

\author{
Budhi Lamtoro, Didi W.U dan Soeharsono \\ Teknik Mesin Universitas Tarumanagara \\ e-mail: Cungkring_speed117@yahoo.com
}

\begin{abstract}
Abstrak: Otomasi industri merupakan hal yang tidak bisa dihindari untuk meningkatkan produktifitas, kualitas dan keselamatan. Oleh karena itu, simulasi mesin otomasi sangatlah penting untuk dibuat agar sistem kerjanya dapat diketahui secara pasti dan dapat dipastikan aman bagi operator. Proses yang biasa digantikan dengan otomasi adalah proses pemindahan barang dan proses pengecekan, sehingga sudah tidak membutuhkan tenaga manual lagi. Modul Storage Station adalah bagian dari mesin simulasi untuk pengecekan. Dibutuhkan PLC untuk mengontrol kedua modul tersebut sehingga dapat berjalan sesuai dengan yang diinginkan. Salah satu bahasa pemrograman yang mudah dimengerti adalah Functional Block Diagram (FBD). Pada FBD, terdapat sebuah metode yaitu metode Sequential Function Chart (SFC) untuk mengatur urutan kerja dari program. Penelitian ini membahas mengenai pengendalian modul Storage Station yang menggunakan bahasa pemrograman FBD dengan menggunakan metode SFC. Hasil yang didapatkan adalah mesin simulasi untuk modul Storage Station dalam skala laboratorium yang mampu mendeteksi material, warna, dan lubang dari benda kerja beserta diagram gerakan dari masing-masing modul.
\end{abstract}

Kata Kunci: Otomasi, Modul Storage Station, Programable Logic Controller, Sequential Function Chart

\begin{abstract}
Industrial Automation is inevitable to improve the productivity, quality and safety. Therefore, the simulation of automation machine is essential to be made so that the work system can be known with certainty and can be determined to be safe for the operator. The process which usually replaced by automation is the process of moving goods and checking process, so it does not require manual labor anymore. Storage Station modules are part of a simulation engine for checking. It needs PLC for controlling both module so that it can run as expected. One of the programming language that is easily understood is the Functional Block Diagram (FBD). In FBD, there is a method which is the Sequential Function Chart method (SFC) to regulate the working order of the program. This research discussed the controlling of Storage Station modules that uses FBD programming language by using SFC method. The result that obtained is the simulation engine for Storage Station module in the laboratory scale that is able to detect the material, color, and the hole of the workpiece along with diagrams of the movements from each module.
\end{abstract}

Keywords: $\quad$ Automation, Storage Station modules, Programable Logic Controller, Sequential Function Chart

\section{PENDAHULUAN}

Otomasi adalah suatu teknologi yang digunakan untuk melaksanakan proses atau prosedur kerja tanpa bantuan manusia. Pekerjaan ini dilakukan dengan menggunakan suatu program instruksi yang dikombinasi dengan suatu sistem pengendali untuk menjalankan instruksi-instruksi tersebut [1]. Berangsur-angsur mesin otomasi menggantikan mesin konvensional. Tujuannya adalah untuk meningkatkan produktivitas kerja, memperbaiki kualitas produk, serta meningkatkan keselamatan kerja. Untuk penyesuaian kebutuhan industri maka sistem dari suatu mesin tersebut pisahkan sesuai dengan kemampuan operasional mesin agar mudah dimodifikasi sistem kerjanya dan mudah diprogram ulang (modular). Oleh karena itu benda kerja yang digunakan dalam suatu sistem haruslah sejenis. Simulasi dari suatu mesin otomasi sangatlah diperlukan dalam pembuatannya agar sistem kerjanya dapat diketahui secara pasti dan dapat dipastikan aman dalam pengopersiannya.

Pada mesin otomasi dan mesin simulasi tersebut, proses pemindahan barang sudah termasuk dalam mesin tersebut sehingga tidak memerlukan tenaga manual untuk memindahkan barang menuju proses selanjutnya. Maka dari itu, sekarang ini bagian atau sektor pemindahan pada suatu proses sudah menggunakan mesin otomasi. Contoh sistem pemindahan antara lain: Sistem Lifting dan Sistem Pushing. 
Untuk mengendalikan pergerakan dan sistem simulasi mesin tersebut, maka dibutuhkan piranti atau peralatan untuk mengatur semua itu. Salah satu piranti yang digunakan secara luas untuk berbagai keperluan pengendali proses adalah Programmable Logic Controller (PLC). Kebutuhan untuk kontroler murah, fleksibel dan mudah telah menghasilkan pengembangan dari programmable logic controller yang dapat digunakan dengan cepat dan dalam berbagai macam aplikasi industri [2].

Oleh karena itu, penulis bertujuan untuk menigkatkan fungsi dari sistem otomasi sebagai suatu alat simulasi didalam industri. Memfungsikan kembali sistem pengendalian modul storage station berbasis sequential function chart ini terdapat beberapa masalah yang harus dijawab untuk menngetahui apakah fungsi dari modul rotary handling station dapat berjalan sesuai dengan keinginan atau tidak, berikut permasalahannya: Menyusun program yang bisa mengatur fungsi dari storage station dan mendeteksi warna pada speciemen untuk di masukan ke dalam storage station yang tersedia.

Permasalahan tersebut dirumuskan dengan bagaimana cara menyatukan kinerja kedua sistem dengan tepat antara sorting dan storage station sehingga sebuah gabungan sistem dapat berkerja sama dan lengan mampu memisahkan bahan antara yang memenuhi syarat dan yang tidak.

Dan tujuannya adalah memberikan simulasi, membuat program yang lebih baik yang sesuai fungsinya dari mesin otomasi storage station dalam aspek laboratorium.

\section{METODE PENELITIAN}

Metode yang dilakukan dalam pembuatan Storage Station adalah pemrograman PLC bersoftware Zelio Soft 2 pada PLC yang digunakan. Modul Storage Station termasuk ke dalam stasiun proses di dalam proses produksi. Modul Storage Station berfungsi untuk mengatur masukan (input) benda kerja dari station sebelumnya yaitu pushing dan lifting yang berfungsi sebagai tempat penyimpanan (storage).

Persiapan awal yang harus diperhatikan adalah sebagai berikut: Membuat sirkuit diagram, membuat perancangan alamat PLC, dan membuat flow charting. Dalam proses penelitian Pengendalian Modul Storage Station Berbasis Sequential Function Chart ini digunakan metode studi literatur. Proses penelitian otomasi ini dilakukan dengan langkah seperti pada Gambar 1.

Bahan yang digunakan dalam perancangan Storage Station ini yaitu : PLC, Air Service Unit, Sensor Photoelectric dan Proximity, Compressor, Solenoid Double Vlave 5/3, Motor 24V DC, Power Supply, Silinder 5/3 dan spesimen benda logam dan non logam.

Adapun terdapat diagram alir yang menjelaskan cara kerja dari modul Storage Station. Sebelum membuat wiring diagram langkah selanjutnya adalah membuat diagram alir. Tahapan kerja pada modul Storage Station adalah berupa siklus. Jadi, modul akan terus berjalan selama masih ada suplai benda kerja yang diberikan. Gambar 2 menjelaskan tahapan gerakan yang terjadi ketika alat eksperimental dijalankan berawal dari start hingga stop (tidak ada benda kerja) untuk modul Storage Station. 

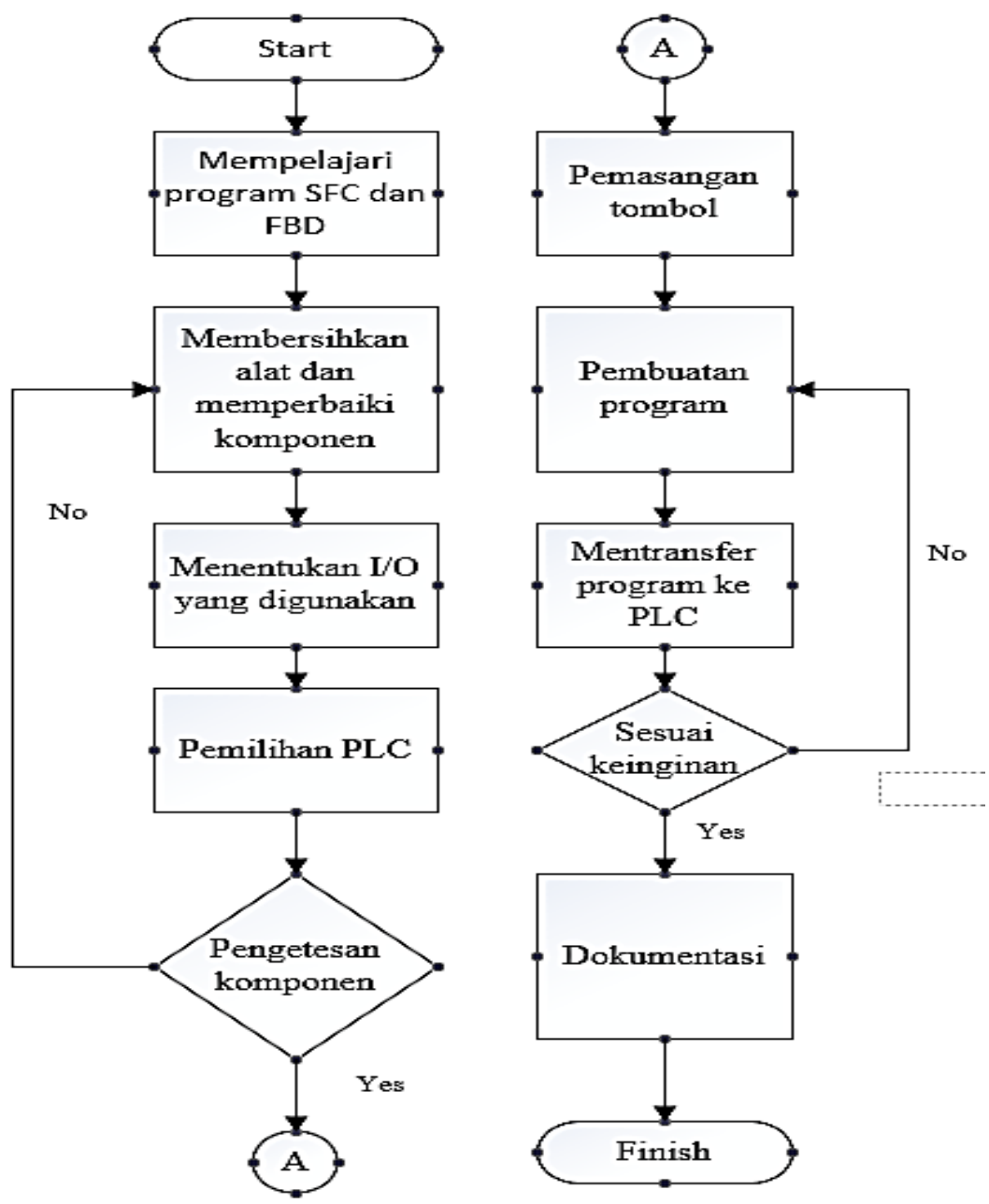

Gambar 1. Diagram alir Proses

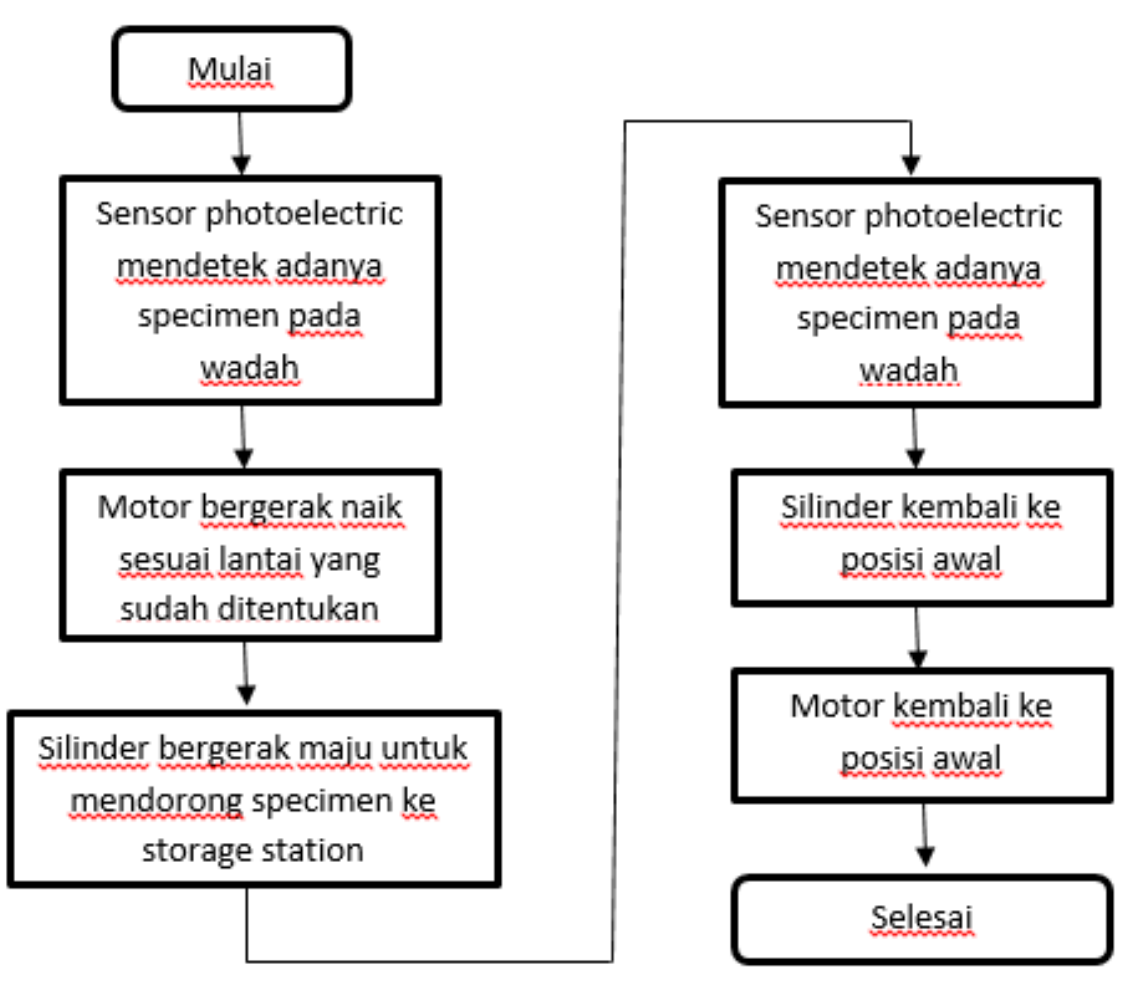

Gambar 2. Diagram Alir Proses 
Storage Station dibuat dengan sistem dasar sebagai berikut:

1) Pada posisi awal limit switch L1 dan sensor proximity P1 akan menyala. Lalu saat specimen diletakan pada wadah (H2 \&H3), maka sensor BD akan menyala yang menandakan adanya benda.

2) Saat itu juga mendapat komunikasi apakah benda itu logam, biru atau berlubang. Saat mendapat komunikasi logam maka motor tidak berkerja namun silinder bekerja maju (sensor P1 ke P2) lalu kembali keposisi awal. Begitu juga bila mendapat komunikasi biru maka motor bergerak naik ke lantai 2 (L1 ke L2) lalu silinder mendorong specimen (P1 ke P2) lalu kembali ke posisi awal P1 dan L1. Begitu juga pada komunikasi lubang akan menuju lantai 3 (L1 ke L3) dan seperti yang lainnya.

3) Silinder dan motor akan kembali ke posisi awal (L1 dan P1) sebagai posisi awal penerimaan specimen dari alat sebelumnya

Program yang dimasukkan dapat dilihat pada Gambar 3.

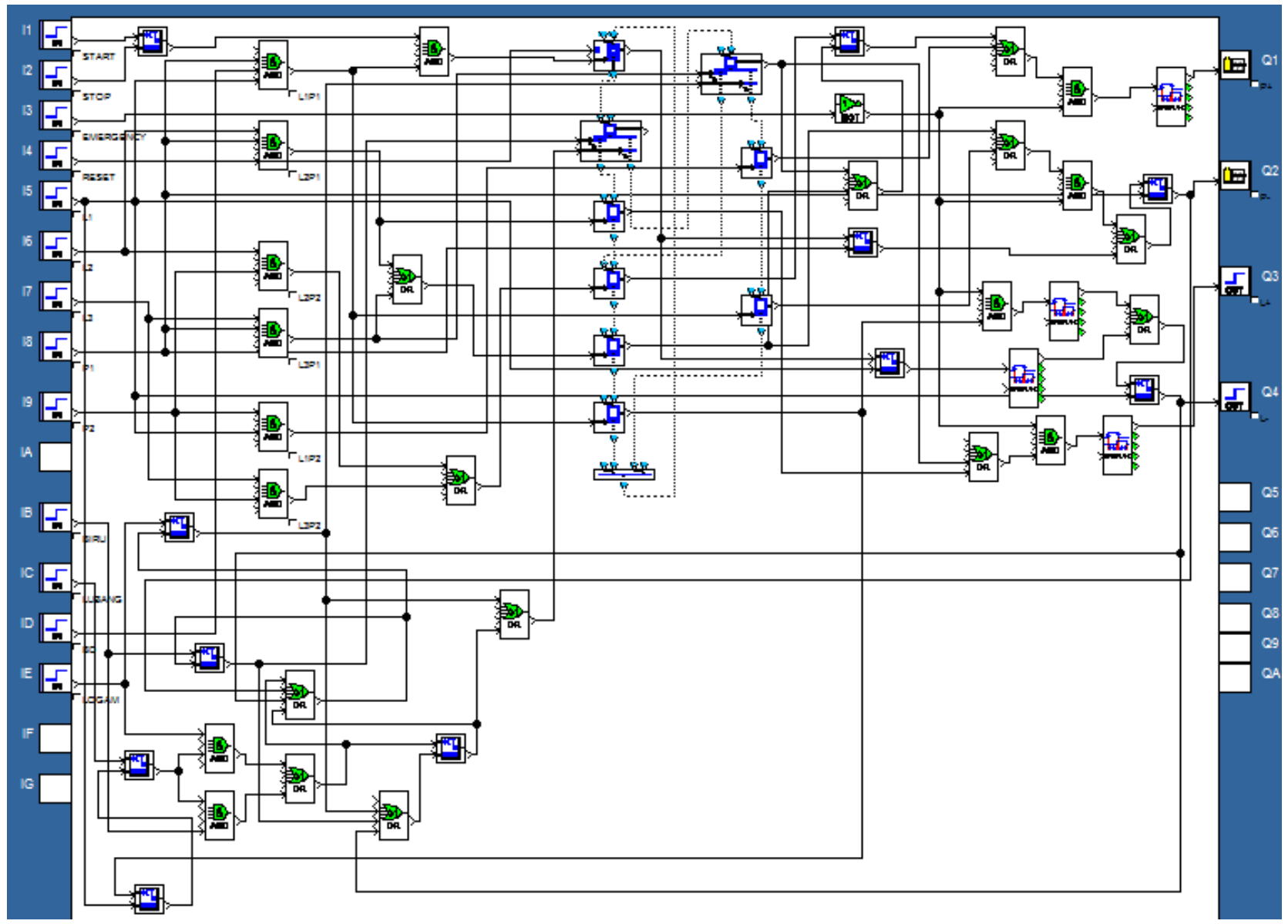

Gambar 3. Program Storage Station

\section{HASIL DAN PEMBAHASAN}

Pengujian modul Storage Station dilakukan setelah perangkaian ulang dan pemrograman PLC. Hasil akhir yang didapat dari beberapa pengujian dan penyesuaian sensor dan program telah sesuai dengan program yang telah dibuat. Langkah dari setiap alat pada station Storage Station dapat dilihat dengan menggunakan diagram step.

Pemrograman mengenai gerakan motor naik dan turun sesuai lantai yang telah di program Storage Station dan sistem silinder untuk mendorong specimen masuk ke Storage Station. Pergeraka ini dimulai dengan menekan tombol start dengan syarat adanya benda pada wadah $\mathrm{H} 2$ atau H3. 
Pengujian ini dilakukan untuk mengetahui waktu dari gerakan benda ketika berpindah lantai menuju lantai sesuai komunikasi yag diterima oleh alat sebelumnya. ketika mendapat komunikasi benda dan sensor benda menyala maka motor dan silinder pun akan bekerja. Prinsip yang akan digunakan pada pengujian ini adalah silinder 1 (silinder pendorong) akan bergerak maju ketika tombol start ditekan dengan syarat adanya benda dengan komunikasi logam di H2 atau H3. Gerakan pengujian pertama dapat dilihat di Gambar 4.
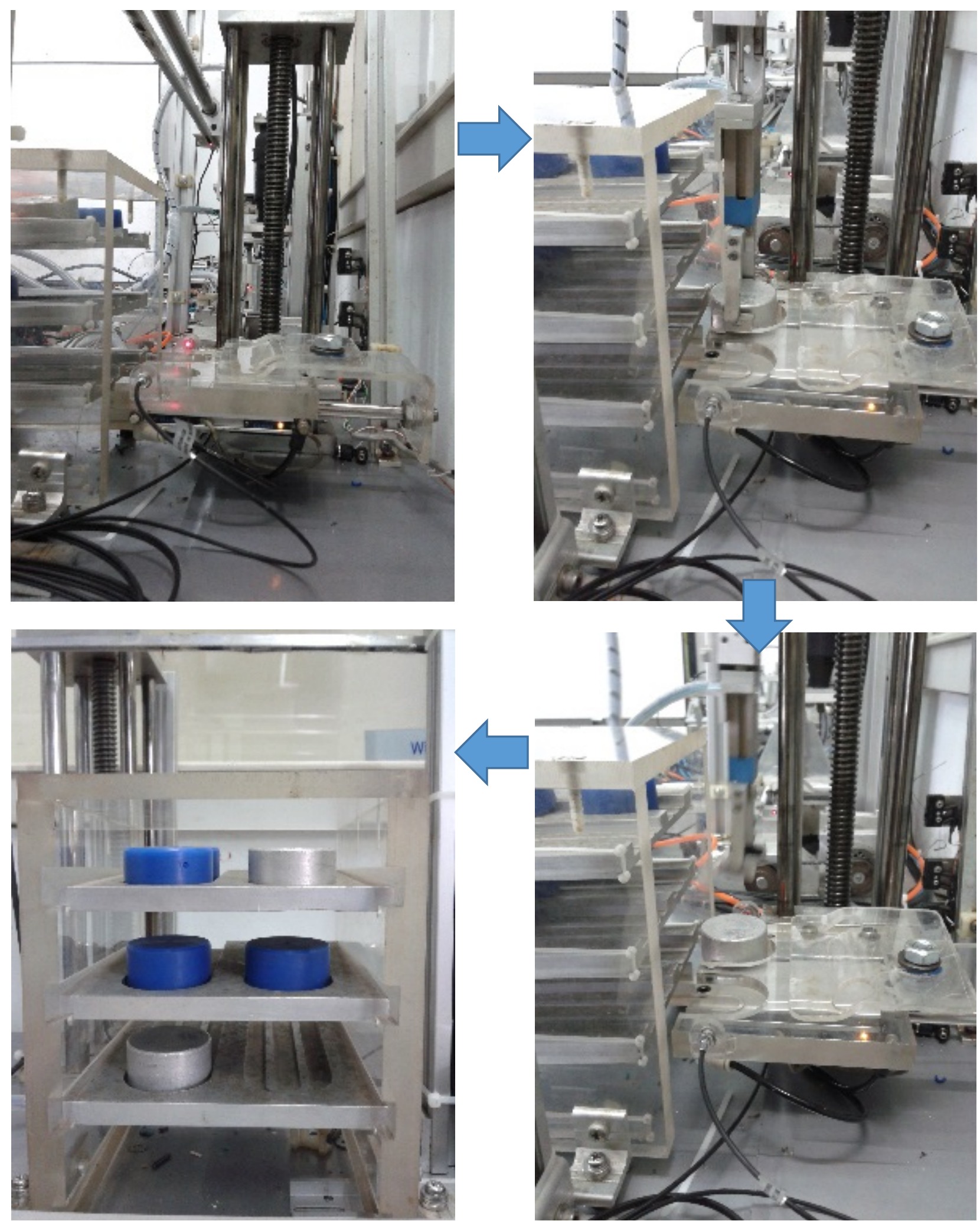

Gambar 4. Gerakan pengujian pertama modul Storage Station 
Berdasarkan pemrograman didapatkan gerakan silinder dan motor lifting seperti di atas. Pada saat tombol "START" ditekan, maka setelah sensor BD aktif valve double solenoid 5/3 dan motor saling berkoordinasi menentukan ke Storage Station lantai 1, 2 atau 3 sesuai program. Jika diketahui benda berupa logam maka motor akan diam dan silinder akan bergerak maju dan setelah sensor P2 aktif maka silinder akan menuju posisi awal pada P1.

Dan jika diketahui benda berupa biru maka setelah sensor benda aktif maka motor akan bergerak naik menuju lantai 2 dan setelah sensor L2 aktif maka silinder akan bergerak maju mendorong benda menuju Storage Station, lalu setelah P2 aktif maka silinder akan kembali ke posisi awal P1 dan motor juga juga akan kembali ke posisi awal pada L1.

Jika diketahui benda itu logam atau biru yang memiliki lubang maka setelah sensor benda aktif maka motor akan bergerak naik menuju lantai 2 dan setelah sensor L3 aktif maka silinder akan bergerak maju mendorong benda menuju Storage Station, lalu setelah P2 aktif maka silinder akan kembali ke posisi awal P1 dan motor juga juga akan kembali ke posisi awal pada L1.

Dalam pengujian modul storage station, pengujian dilakukan sebanyak 8 kali sehingga diperoleh catatan waktu pengantaran benda ke posisi akhir dan waktu kembali ke posisi awal yang dapat dilihat pada Tabel 1.

Tabel 1. Hasil Pengujian

\begin{tabular}{ccc}
\hline No & $\begin{array}{c}\text { Awal - akhir } \\
(\mathrm{s})\end{array}$ & $\begin{array}{c}\text { Akhir - awal } \\
(\mathrm{s})\end{array}$ \\
\hline 1 & 6,67 & 3,78 \\
2 & 6,58 & 3,75 \\
3 & 6,53 & 3,74 \\
4 & 6,57 & 3,70 \\
5 & 6,65 & 3,68 \\
6 & 6,63 & 3,74 \\
7 & 6,64 & 3,78 \\
8 & 6,67 & 3,76 \\
\hline$\Sigma$ & 6,61 & 3,74 \\
\hline
\end{tabular}

Berdasarkan hasil pengujian sensor bagian pengecekan tersebut, diketahui bahwa sensorsensor bagian pengecekan bekerja dengan sangat baik sehingga didapatkan hasil $100 \%$ sesuai dengan benda yang diuji.

\section{KESIMPULAN}

Berdasarkan hasil pengujian modul storage station berbasis sequential function chart ini, didapat beberapa kesimpulan antara lain:

1. Proses pada storage station efisien waktu sebesar $62,5 \%$ dari satu siklus penuh (cycle time).

2. Kinerja modul storage station sudah mencapai kinerja yang baik dengan ketepatan distribusi sebesar $100 \%$ pada 8 kali pengujian (repeat ability).

3. Semua peralatan dan program sequential function chart dinyatakan berhasil karena sistem berjalan sesuai rencana dalam skala laboratorium.

4. Jumlah I/O PLC = 16 input, 10 output. Yang digunakan dalam modul storage station ini adalah 14 input dan 4 output serta jumlah program yang digunakan berjumlah 1 program.

5. Waktu kerja yang dibutuhkan satu siklus untuk satu benda kerja:

- Waktu pengantaran benda ke posisi akhir = 6,73 detik

- Waktu kembali = 3,24 detik 


\section{DAFTAR PUSTAKA}

[1] Groover M. P., Automation, Production Systems, and Computer-Integrated Manufacturing, 2nd ed, New Jersey: Prentice-Hall,Inc., 2001.

[2] Aanajja’s ,"Pengertian Dan Perbedaan Sistem Mesin Hidrolik Dan Pneumatik,” [Online]. [Diakses September 2014]

[3] Rudy D.E “Sistim Kontrol Digital Pada Storage Station Dengan Menggunakan PLC” 2002.

[4] W. Bolton, Programming Logic Controllers, Fourth edition 2006. Burlington: Elsevier Newnes,.

[5] Siemens, Function Block Diagram (FBD) for S7-300 and S7-400 Programming, Germany: Siemens AG, 2006.

[6] N. Permana, F. Hendra, Leonardus, skripsi: “ Perancangan Konseptual Sistem Transfer Pada Processing Work Station” 2001.

[7] H.Khasawneh, Introduction to PLC and Ladder Logic, Amman: Faculty of Engineering and Technology University Of Jordan, 2009.

[8] Rusli Sucipto, skripsi:”Pengontorlan Pada Lengan Pemindah Bahan”,2001.

[9] Rozan, Amran. "Aplikasi PLC Merek Omron Sysmac CP1A pada Sistem Gerak Otomatis Pintu Garasi Mobil”. Jurnal Teknik SIMETRIKA. 4. (1). 296-302.

[10] Khurmi, R.S. dan J.K. Gupta. A Textbook of Machine Design. New Delhi: Eurasia, 2005 